\title{
Rehabilitation of periscapular malignant soft-tissue tumors after partial scapulectomy, wide resection and split-thickness skin grafting: A case report
}

Yudai Fujimoto $^{1 *}$ and Hironari Tamiya ${ }^{1,2}$

*Correspondence: hironari.tamiya@oici.jp

CrossMark

$\leftarrow$ Click for updates

'Department of Rehabilitation, Osaka International Cancer Institute, Japan.

${ }^{2}$ Department of Orthopedic Surgery, Osaka International Cancer Institute, Japan.

\begin{abstract}
Background: Wide resection of malignant bone and soft-tissue tumors of the extremities may impair the functions of the affected limbs. Partial scaplectomy affects shoulder movements, resulting in disabilities that interfere with activities of daily living.

Methods: Rehabilitation treatment of a man in his 70 s with periscapular malignant soft-tissue tumors subjected to extensive resection with partial scapular resection and split-thickness skin grafting was conducted. Postoperative rehabilitation included early mobilization, range of motion exercises, strength training of the residual muscles, and activities of daily living training. Rehabilitation assessments of physical function, patient-based outcomes, and quality of life were performed preoperatively and at 1, 3,6 months and 1 year postoperatively.

Results: Preoperative function of the affected limb was determined to be $86.7 \%$ using the Musculoskeletal Tumor Society Rating Scale score (MSTS), 97.4\% using the Toronto Extremity Salvage Score (TESS), and mildly limited in shoulder elevation. The patient was discharged from the hospital approximately 1 month postoperatively. Postoperative shoulder elevation was less than half of the preoperative level, with MSTS in the 30-40\% range and TESS in the 60-70\% range. Postoperatively, the patient could perform activities of daily living independently, but only with the use of compensatory movements and devices distal to the elbow.

Conclusions: After wide tumor resection with loss of skeletal and muscular structures around the shoulder joint including the scapula, postoperative rehabilitation may require maintenance of shoulder immobilization with the residual muscles and efficient use of modified movements distal to the elbow to achieve better function in real-life situations.
\end{abstract}

Keywords: Scapula, malignant tumor, upper limb function, rehabilitation

\section{Introduction}

Although surgical resection is the mainstay of treatment for bone and soft-tissue tumors, wide resection may result in a massive soft-tissue defect to secure sufficient excision margins [1]. Functional impairment in a postoperative state occurs according to the degree of resected tissue. Thus, appropriate rehabilitation is required to achieve good activities of daily living (ADL) and quality of life outcomes $[2,3]$.

Bone and soft-tissue tumors in the shoulder girdle including the scapula may require total or partial scapulectomy. Involvement of rehabilitation therapists before and after scapulectomy is integral for preparing for surgery and subsequent treatment [4]. The functional outcome of partial scapulectomy is significantly higher than that of total scapulectomy [5]. In case of total scapulectomy, postoperative management may require comprehensive rehabilitation to improve not only upper extremity functions but also gait deficits associated with changes in the body composition [6]. In contrast, upper limb function 
after partial scapulectomy is generally excellent [7] and ADL impairment is often less common [8]. Therefore, rehabilitation after partial scapulectomy is generally less difficult.

Here, we report a case of malignant soft-tissue tumor affecting the left shoulder girdle treated with partial scapulectomy and wide resection of the periscapular malignancy, as well as split-thickness skin grafting, with poor postoperative upper extremity function outcome.

\section{Case presentation}

Written informed consent was obtained from the patient for publication of this case report.

\section{Patient}

The patient was a right-handed man in his 70s, with a height of $172.2 \mathrm{~cm}$, weight of $71.8 \mathrm{~kg}$, and body mass index of $24.2 \mathrm{~kg} / \mathrm{m}^{2}$.

\section{Social background}

The patient lives with his wife and runs his own online trade company.

\section{Disease}

Left upper back soft-tissue sarcoma (histology: undifferentiated pleomorphic sarcoma).

\section{Present illness}

A patient noticed a nodule on his left side and visited a clinic. Marginal resection was performed; however, the subcutaneous tumor had been rapidly growing, and a soft-tissue sarcoma was diagnosed. He then visited our hospital for more specialized treatment. Wide resection was necessary and he consented to undergoing his surgery.

\section{Operative findings}

His surgery was performed in the prone position under general anesthesia. A $19 \mathrm{~cm} \times 28 \mathrm{~cm}$ skin incision was made over the tumor. The trapezius, teres major, and infraspinatus muscles were partially resected, along with the lower part of the scapula and part of the spinal process. A part of the scapula exposed due to a lack of soft-tissue was covered with the subscapularis muscle. A split-thickness skin graft was performed, followed by vacuum-assisted closure (VAC) device to fix the grafted skin. The total operation time was $7 \mathrm{~h}$ and $30 \mathrm{~min}$ (Figure 1).

\section{Clinical course of rehabilitation treatment}

Preoperative examination revealed a $10-\mathrm{cm}$ elastic hard mass on his back. The range of motion (ROM) of the left shoulder was $160^{\circ}$ in flexion and $150^{\circ}$ in abduction (Figure 2). During elevation and abduction of the shoulder joint, the scapulohumeral rhythm was intact.Mild muscle weakness (manual muscle test score, 4) was observed in flexion and abduction of the left shoulder.

During the first 2 weeks post-surgery, left shoulder immobilization was necessary to avoid skin graft failure. In the
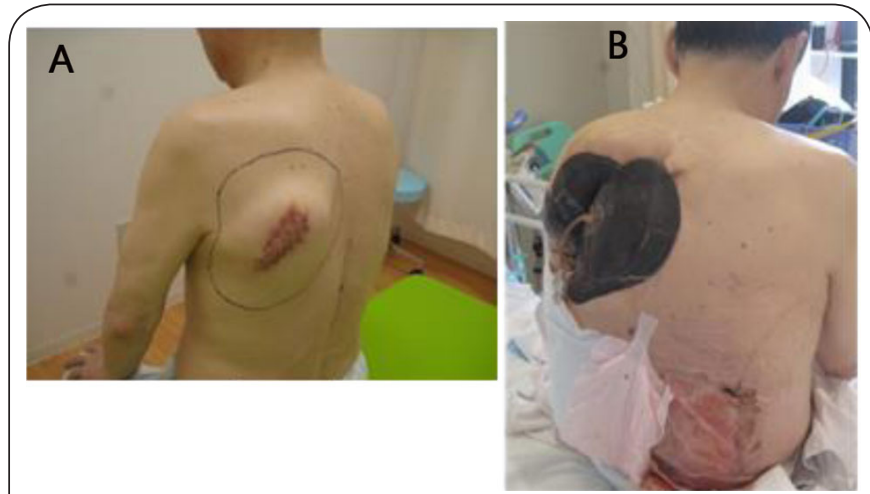

Figure 1. A periscapular malignant soft-tissue tumor in the left shoulder.

Macroscopic preoperative (A) and postoperative (B) images.
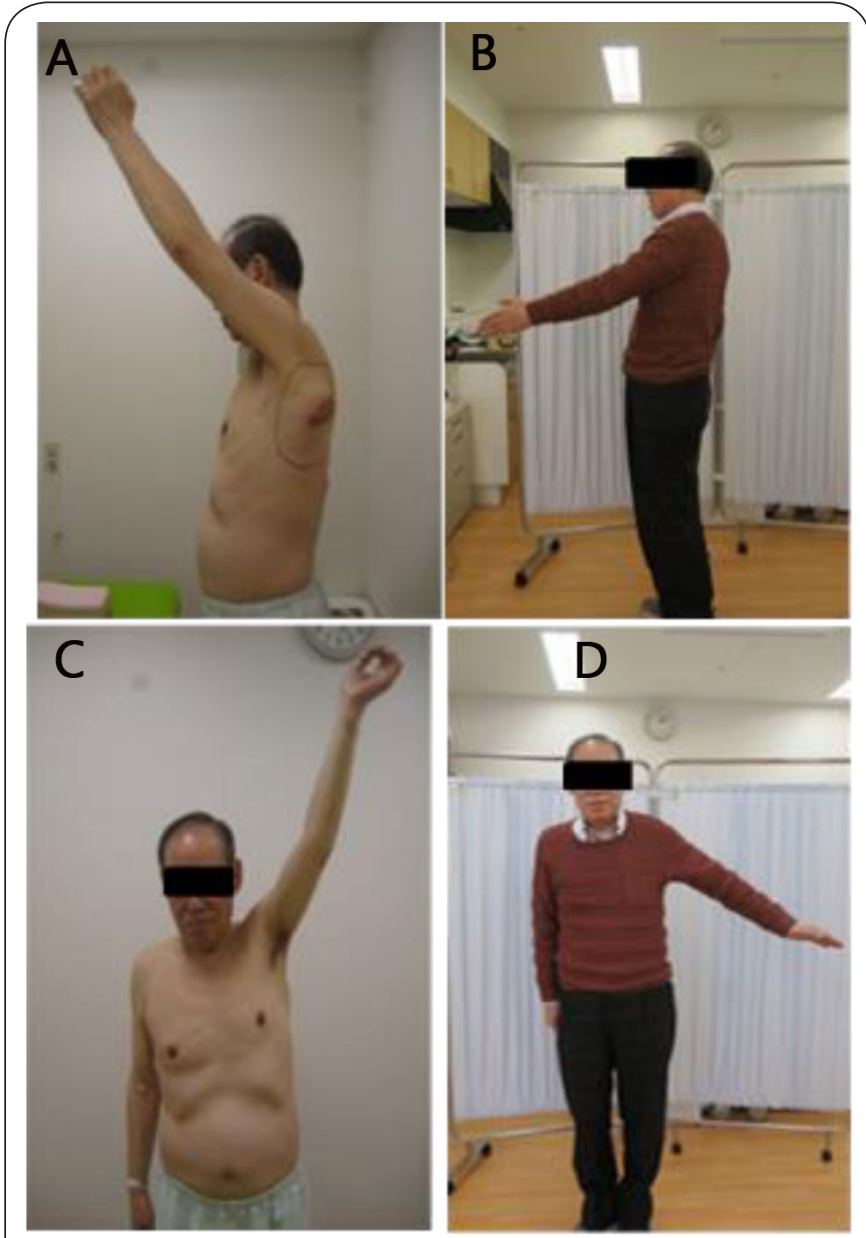

Figure 2. Range of motion of the shoulder.

(A) Preoperative shoulder flexion; (B) shoulder flexion at 1 year after surgery; (C) preoperative shoulder abduction; and (D) shoulder abduction at 1 year after surgery.

meantime, gait exercise and self-care training using his right arm and exercise below the left elbow were conducted.

In the third week post-surgery, the VAC was removed and 
left shoulder exercise was permitted. At that point, the ROM of the left shoulder was severely impaired (active flexion, $40^{\circ}$; active abduction, $\left.40^{\circ}\right)$. Active and passive exercises were initiated on the left shoulder, and active usage of the left arm was encouraged. Physical therapy for left shoulder function was started with grip strength exercises, Codman exercises, and wiping training and then stepped up to active assisted movements, active movements, and material handling exercises as well as strength training of the residual muscles with isometric training and isotonic training (Figure 3). With rehabilitation treatment during hospitalization, both active flexion and abduction of the shoulder improved to approximately $70^{\circ}$. However, because of shoulder elevation difficulties, the use of movements distal to the elbow mainly was necessary to regain the $A D L$ function. ROM and muscle strength below the left elbow were intact in a postoperative state. Eventually, rehabilitation of his left arm distal to the elbow enabled reaching movement to his mouth and overhead. In addition, compensatory actions and operation methods were needed. For example, face and hair washing required more forward bending of the trunk than usual. The dressing and undressing of the upper garment needed to be modified in the same way as for hemiplegic patients. For example, the patient practiced how to put on a shirt with the sleeve from the paralyzed side and take off the shirt from the healthy side. Changing the upper garment had to be performed in a similar way to a hemiplegic patient after stroke. The patient could operate a computer but was required to do so while having his elbows positioned on the desk to reduce fatigue (Figure 3). The patient was discharged from the hospital 29 days after surgery. At discharge, the patient's all ADL was achieved independently and early return to work after discharge was achieved.

Intensity-modulated radiation therapy (IMRT) (60 Gy in 30 fractions) was performed at 6 weeks post-surgery. Rehabilitation treatment continued in the outpatient clinic until 1 year post-surgery because IMRT may lead to a reduction in the ROM due to fibrous changes that occur in irradiated soft tissues. At the final 1-year follow-up, the patient's shoulder motion remained limited (active flexion, $70^{\circ}$; active abduction, $70^{\circ}$ ) and the shrug sign remained (Figure 2). Several of his functional parameters and scores during the follow-up period are shown in Table 1.

\section{Discussion}

The clinical course of this case's rehabilitation provided two important clinical considerations. First, postoperative shoulder

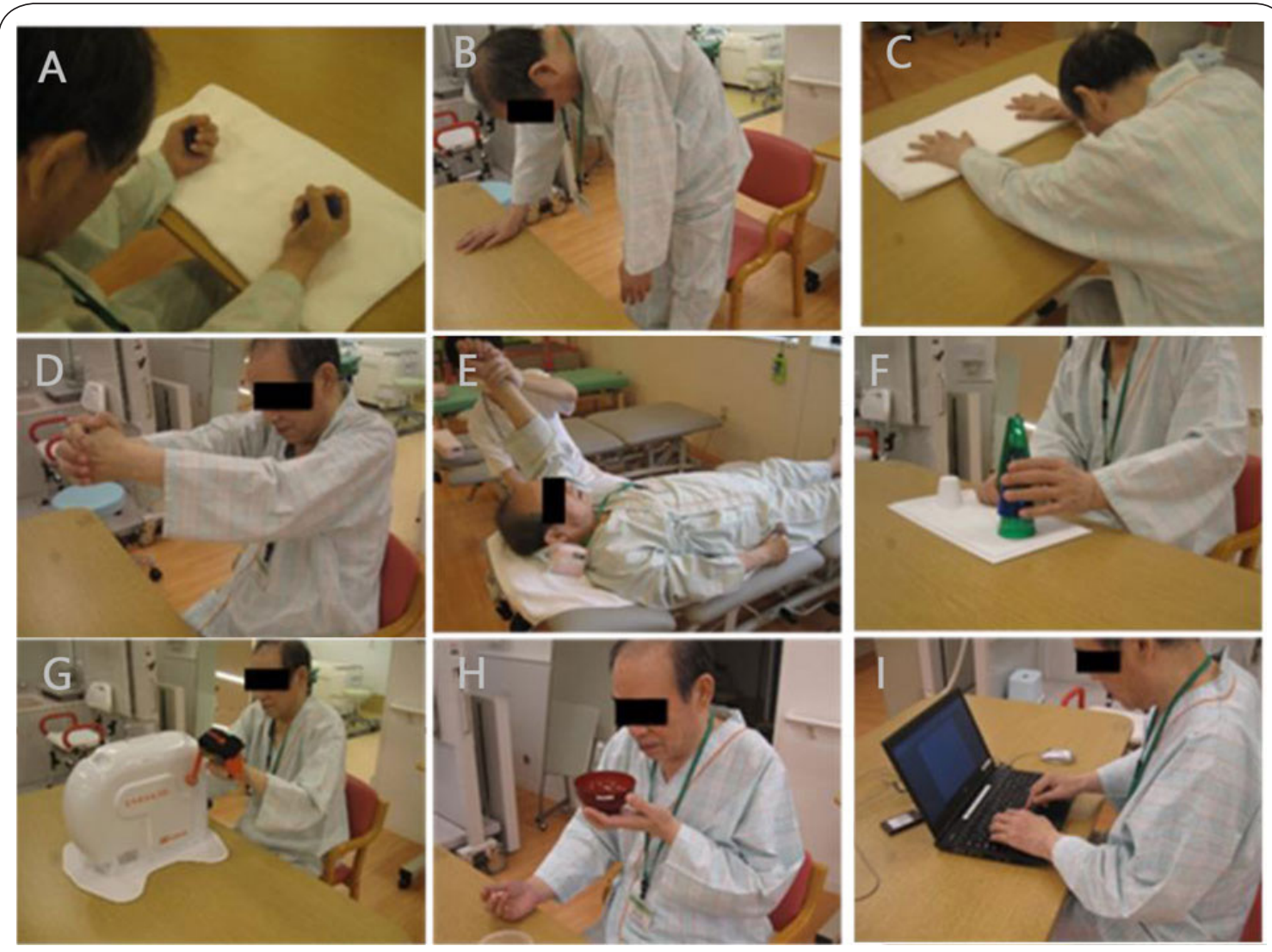

Figure 3. Rehabilitation treatment of the upper extremity.

(A) Grip strength exercise; (B) Codman exercise; (C) wiping training; (D) active assistive movement; (E) passive movement; (F) active movement and material handling exercises; $(\mathbf{G})$ upper-extremity ergometer; and $(\mathbf{H})$ rehabilitation of activities of daily living (ADL) and instrumental ADL including self-feeding and typing. 
Fujimoto et al, Physical Therapy and Rehabilitation 2021,

Table 1. Preoperative and postoperative values for functional outcomes

\begin{tabular}{lccccc}
\hline & $\begin{array}{c}\text { Pre } \\
\text { operative }\end{array}$ & $\begin{array}{c}\text { Post } \\
1 \text { month }\end{array}$ & $\begin{array}{c}\text { Post } \\
3 \text { months }\end{array}$ & $\begin{array}{c}\text { Post } \\
6 \text { months }\end{array}$ & $\begin{array}{c}\text { Post } \\
\text { 1 year }\end{array}$ \\
\hline Pain (NRS) pain at rest / in motion & $1 / 2$ & $1 / 4$ & $2 / 7$ & $2 / 7$ & $3 / 7$ \\
active ROM $\left(^{\circ}\right.$ ) & & & & & \\
shoulder flexion & 160 & 75 & 70 & 60 & 70 \\
shoulder abduction & 150 & 80 & 65 & 60 & 70 \\
Grip strength(kg) & 37.4 & 28.9 & 26.1 & 20.8 & 24.3 \\
STEF of left upper extremity(score) & 96 & 85 & 93 & 90 & 96 \\
& & & & & \\
MSTS(\%) & 86.7 & 46.7 & 46.7 & 36.7 & 43.3 \\
TESS(\%) & 97.4 & 77.6 & 60.3 & 75 & 64.7 \\
DASH-Disability/Symptom(score) & 20.0 & 40.0 & 69.2 & 70 & 65.8 \\
DASH-Work(score) & 0 & 25.0 & 25.0 & 25.0 & 18.8 \\
EQ5D5L & 0.895 & 0.777 & 0.678 & 0.704 & 0.504 \\
\hline
\end{tabular}

NRS: numerical rating scale, ROM: range of motion, MMT: munual muscle test, STEF: simple test for evaluating hand function, MSTS: musculoskeletal tumor society, TESS: tronto extremity salvage score,

DASH: disabilities of the arm, shoulder and hand

elevation is poor after partial scapulectomy together with wide resection of periscapular malignancy, as well as split-thickness skin grafting. As mentioned above, functional outcome after partial scapulectomy is generally excellent. Among the classifications of scapulectomy,resection of the lower part of the scapula had the best postoperative function [9]. Therefore, in this case, wide resection and concurrent split-thickness skin grafting, together with partial scapulectomy, likely had a negative impact on upper extremity functions. This wide resection involved removal of the trapezius, lattismusdorsi, teres major, teres minor, and subscaplaris muscles with the tumor.

Resected muscles, such as the rotator cuff, are related to shoulder joint dysfunctions [8]. Shoulder flexion can be divided into three phases. The first phase is flexion $0^{\circ}-60^{\circ}$, in which the infraspinatus muscle pulls the humeral head to the glenoid, and the deltoid and coracobrachialis muscles elevate the arm. The second phase is flexion $60^{\circ}-120^{\circ}$, in which the shoulder girdle maintains the elevation [10]. The final phase is flexion $120^{\circ}-180^{\circ}$, in which the deltoid, supraspinatus, trapezius, and serratus muscles with the vertebral spine control arm elevation. Following this kinematics, this case may be impaired in the second (flexion $60^{\circ}-120^{\circ}$ ) and third (flexion $120^{\circ}-180^{\circ}$ ) phases. In addition, scapulohumeral rhythm requires movement at a ratio of 2:1 in the upper arm and shoulder girdle $[11,12]$. In this case, the lower part of the scapula and part of the muscle that abducts the scapula were excised, which may have impaired scapular motion. Another concern is that splitthickness skin grafts may cause a loss of skin elasticity and tissue contracture [13]. Moreover, IMRT also triggers a fibrous change in the irradiated tissue, leading to limited ROM [14]. Scapulectomy has been frequently reported for bone tumors of the primary scapula, with few reports on soft-tissue tumors. Therefore, different functional outcomes should be considered when peri-muscular resection, implantation, or radiotherapy is performed along with scapulectomy, as in the present case.

Second, to regain ADL function, effective use of preserved movements distal to the elbow is essential. The loss of ROM in the shoulder interferes with ADL. A systematic review reported that at least approximately $130^{\circ}$ shoulder flexion and abduction was necessary for good ADL capacity [15]. In this case, at 1 year postoperatively, the patient had approximately $70^{\circ}$ of shoulder flexion and abduction and could not naturally perform ADL. Therefore, establishment of compensatory actions and altered operation methods was helpful in improving ADL skills. In some cases, occupational rehabilitation should also be performed if a job change is necessary. In contrast, motions distal to the elbow are often maintained even when the shoulder joint is dysfunctional [16-18]. To ensure a good outcome, it is essential to effectively elicit fine motions below the elbow rather than shoulder motion. In this case, no functional impairment of the distal to the elbow was observed 
Fujimoto et al, Physical Therapy and Rehabilitation 2021,

and rehabilitation of the arm distal to the elbow as well as the shoulder actually enabled independent self-care including reaching movement to his mouth and overhead.

\section{Conclusion}

Postoperative shoulder elevation is poor after partial scapulectomy together with wide resection of periscapular malignant, as well as split-thickness skin grafting. Therefore, the effective use of movements distal to the elbow is important to improve ADL functions. For rehabilitation therapists, attention to poor shoulder functions postoperatively is necessary, and importance of early rehabilitation for preserving movements distal to the elbow should be considered.

\section{Competing interests}

The authors declare that they have no competing interests.

Authors' contributions

\begin{tabular}{|l|c|c|}
\hline Authors' contributions & HT & YF \\
\hline Research concept and design & $\checkmark$ & $\checkmark$ \\
\hline Collection and/or assembly of data & -- & $\checkmark$ \\
\hline Data analysis and interpretation & $\checkmark$ & $\checkmark$ \\
\hline Writing the article & $\checkmark$ & $\checkmark$ \\
\hline Critical revision of the article & $\checkmark$ & $\checkmark$ \\
\hline Final approval of article & $\checkmark$ & $\checkmark$ \\
\hline Statistical analysis & -- & $\checkmark$ \\
\hline
\end{tabular}

\section{Publication history}

Editor: Catherine Ortega, University of Texas Health Science Center, USA. Received: 29-Nov-2020 Final Revised: 22-Jan-2021

Accepted: 28-Jan-2021 Published: 19-Feb-2021

\section{References}

1. Ogura K, Higashi T, Kawai A. Statistics of bone sarcoma in Japan: Report from the Bone and Soft Tissue Tumor Registry in Japan. J Orthop Sci. 2017,22:133-143.

2. Weschenfelder W, Gast-Froehlich S, Spiegel C, Vogt M, Hofmann $\mathrm{GO}$. Factors influencing quality of life, function, reintegration and participation after musculoskeletal tumour operations. BMC Cancer. 2020,20:351.

3. Silva RS, Guilhem DB, Batista KT, Tabet LP. QUALITY OF LIFE OF PATIENTS WITH SARCOMA AFTER CONSERVATIVE SURGERY OR AMPUTATION OF LIMBS.ActaOrtop Bras. 2019, 27:276-280.

4. Ward B, McGarvey $C$, Lotze MT. Excellent shoulder function is attainable after partial or total scapulectomy. Analysis at prolonged follow-up. Arch Surg. 1990,125:537-42.

5. Griffin AM, Shaheen M, Bell RS, Wunder JS, Ferguson PC. Oncologic and functional outcome of scapular chondrosarcoma. Ann SurgOncol. 2008,15:2250-6.

6. Vitale KC, Jimenez A. Rehabilitation after scapulectomy. Am J Phys Med Rehabil. 2009,88:267-71.

7. Gibbons CL, Bell RS, Wunder JS, Griffin AM, O'Sullivan B, Catton CN, Davis AM. Function after subtotal scapulectomy for neoplasm of bone and soft tissue. J Bone Joint Surg Br. 1998,80:38-42.

8. Nota SP, Russchen MJ, Raskin KA, Mankin HJ, Hornicek FJ, Schwab JH. Functional and oncological outcome after surgical resection of the scapula and clavicle for primary chondrosarcoma. Musculoskelet Surg. 2017,101:67-73.

9. Hayashi K, Iwata S, Ogose A, Kawai A, Ueda T, Otsuka T, Tsuchiya H. Factors that influence functional outcome after total or subtotal scapulectomy: Japanese Musculoskeletal Oncology Group (JMOG) study.PLoS One. 2014,9:e100119.

10. I.A.Kapandji: The Physiology of the Joints, Volume 1: Upper Limb. Churchill Livingstone,1983,64-67.

11. Codman EA: The Shoulder. (eds. Thomas Todd). G. Miller \& Company, 1934,32-64.

12. Inman VT, Abbott LC: Observations on the function of the shoulder joint. J Bone Joint Surg Am 1944,26: 1-30.

13. Malawer M., Wittig J., Rubert C. Scapulectomy. In: Musculoskeletal Cancer Surgery. Springer, Dordrecht,2004;553-568.

14. Yang JC, Chang AE, Baker AR, Sindelar WF, Danforth DN, Topalian SL, DeLaney T, Glatstein E, Steinberg SM, Merino MJ, Rosenberg SA. Randomized prospective study of the benefit of adjuvant radiation therapy in the treatment of soft tissue sarcomas of the extremity. J ClinOncol. 1998,16:197-203.

15. Oosterwijk AM, Nieuwenhuis MK, van der Schans CP, Mouton LJ. Shoulder and elbow range of motion for the performance of activities of daily living: A systematic review. Physiother Theory Pract. 2018,34:505-528.

16. Nakamura S, Kusuzaki K, Murata H, Takeshita H, Hirata M, Hashiguchi $S$, Hirasawa Y. Clinical outcome of total scapulectomy in 10 patients with primary malignant bone and soft-tissue tumors. J SurgOncol. 1999,72:130-5.

17. Puchner SE, Panotopoulos J, Puchner R, Schuh R, Windhager R, Funovics PT. Primary malignant tumours of the scapula--a review of $\mathbf{2 9}$ cases. IntOrthop. 2014,38:2155-62.

18. O'Connor MI, Sim FH, Chao EY. Limb salvage for neoplasms of the shoulder girdle. Intermediate reconstructive and functional results. J Bone Joint Surg Am. 1996,78:1872-88.

\section{Citation:}

Fujimoto $\mathrm{Y}$ and Tamiya $\mathrm{H}$. Rehabilitation of periscapular malignant soft-tissue tumors after partial scapulectomy, wide resection and split-thickness skin grafting: A case report. Phys Ther Rehabil. 2021; 8:2.

http://dx.doi.org/10.7243/2055-2386-8-2 